\title{
A Novel Biomarker for Cellular Toxicity and Phospholipid Accumulation by Cationic Amphiphilic Drugs
}

\author{
Ryohei HAMAGUCHI, Yukihiro KURODA* \\ School of Pharmacy and Pharmaceutical Sciences, Mukogawa Women's University, \\ 11-68 Koshien-kyubancho, Nishinomiya 663-8179, Japan
}

\begin{abstract}
Drug-induced phospholipidosis (DIPL) is a phospholipid-hyperaccumulated state in cells, tissues and organs after treatment with cationic amphiphilic drugs (CADs). The biological meaning of phospholipidosis remains unknown. Although a hypothesis has been proposed that DIPL is a biological defense from CADs, experimental data supporting the hypothesis are poor. In this study, we compared CAD toxicity with RAW264 cells with/without egg phosphatidylcholine (egg PC) treatment to identify the role of phospholipids in DIPL. The $50 \%$ inhibitory concentrations of chlorpromazine, imipramine and propranolol were significantly increased by egg PC, in accordance with the hypothesis. Then, DIPL biomarkers, bis(monoacylglycero)phosphate (BMP) and the ratio of phosphatidylinositols (PIs) were measured to study the changes of these biomarkers by the relief of CAD toxicity with egg PC. BMP 22:6_22:6 was not increased by imipramine treatment alone due to imipramine toxicity. Co-treatment of egg PC with imipramine did not decrease BMP 22:6_22:6, which was inconsistent with the relief of toxicity. Conversely, the ratio of PIs increased by imipramine treatment alone, whereas it decreased by co-treatment with egg PC. These results suggest that the ratio of PIs reflects cellular phospholipid accumulation concurrent with CAD toxicity and that it is useful as a DIPL biomarker with high specificity.
\end{abstract}

Keywords: Drug-induced phospholipidosis; Bis(monoacylglycero)phosphate; Phosphatidylinositol

\section{Introduction}

Drug-induced phospholipidosis (DIPL) is caused by repetitive administration of cationic amphiphilic drugs (CADs). When DIPL occurs, lamellar bodies, which are concentric structures formed with excessive phospholipid, are found in various tissues and organs, including the lungs, liver, brain, kidneys and corneas [1-3]. Experimentally, phospholipid accumulation is also observed in cultured cells, even after a single treatment with CADs [4,5]. Although the biological meaning of phospholipid accumulation is not understood, studies have reported that CADs strongly interacts with phospholipid [6-10] and that CADs are accumulated in lamellar bodies [4]. From these observations, a hypothesis has been proposed that DIPL works as a biological defense against CADs [1]. According to this hypothesis, exogenous CADs are isolated and stored in lamellar bodies, resulting in reduction of their

${ }^{*}$ Corresponding author: Yukihiro KURODA

Tel: +81-798-45-9950; Fax: +81-798-45-9950

E-mail: kurodada@mukogawa-u.ac.jp toxicity. However, there are no reports on the effect of phospholipid accumulation on CAD toxicity in vivo or in cultured cells. The first objective of this study is to elucidate whether CAD toxicity to cultured cells is lowered by phospholipid.

Electron microscopy is the gold standard for diagnosis of DIPL, with which lamellar bodies are visualized in biopsy samples. Compared with other methods, electron microscopy is superior in the direct detection of lamellar bodies. The method is, however, invasive, laborious and time-consuming. Therefore, biomarkers to monitor the progression of DIPL are needed. To date, several biomarkers, including phenylacetylglycine [11], sets of genomic biomarkers [12-14] and bis(monoacylglycero)phosphate (BMP) $[15,16]$, have been reported. In addition to these biomarkers, it was reported that the ratio of phosphatidylinositols could be used to

Received: 27 October 2015

Accepted: 13 December 2015

J-STAGE Advance Published: 21 December 2015

DOI: $10.15583 /$ jpchrom.2015.033 
monitor the progression of phospholipid accumulation after CAD treatment [17]. According to Hamaguchi et al., after treatment of cultured cells with CADs, the ratios of PI 36:1 and PI 36:2 over PI 38:3 and PI 38:4 increases with an increase of cellular phospholipid content [17]. In the present study, we studied how the biomarkers changed by phospholipid accumulation and cellular toxicity by CADs.

\section{Experimental}

\subsection{Chemicals and cell culture}

In this study, imipramine, propranolol and chlorpromazine were used as model CADs. Imipramine hydrochloride (>98\%), propranolol hydrochloride (>98\%), reserpine (> 99\%), egg phosphatidylcholine (egg PC), methanol (LC-MS grade) and RPMI-1640 supplemented with L-glutamine were purchased from Wako Pure Chemical Industries (Osaka, Japan). Chlorpromazine hydrochloride (USP grade) and ammonium formate (97\%) were purchased from Sigma-Aldrich (St. Louis, MO, USA). 3-(4,5-Dimethyl-2-thiazolyl)-2,5-diphenyl-2 $H$-tetrazolium bromide (methyl thiazolyl tetrazolium, MTT) was obtained from Dojindo Laboratories (Mashiki, Japan). 1,2-Diheptadecanoyl-sn-glycero-3-phosphocholine (PC 17:0_17:0, > 99\%) was purchased from Avanti Polar Lipids (Alabaster, AL, USA). Other chemicals of analytical grade were from local suppliers.

RAW264 cells were provided from RIKEN BRC (Tsukuba, Japan) and were grown in RPMI-1640 with L-glutamine containing $10 \%$ fetal bovine serum and penicillin-streptomycin (GIBCO; Invitrogen) at $37{ }^{\circ} \mathrm{C}$ in a humidified atmosphere with $5 \% \mathrm{CO}_{2}$.

\subsection{MTT assay}

RAW264 cells were harvested when semi-confluent in 96-well plates. Then, the cells were treated with CAD alone or with egg PC (2 mM) for $48 \mathrm{~h}$. MTT containing fresh culture medium (MTT $0.05 \mathrm{w} / \mathrm{v} \%$ ) was then used for the CAD-treated cells. After $3 \mathrm{~h}$ incubation, the MTT-containing medium was removed, and isopropanol containing hydrochloric acid $(0.04 \mathrm{~mol} / \mathrm{L})$ was added to solubilize reaction product. The absorbance at $570 \mathrm{~nm}$ was measured with a microplate reader (Sunrise Remote; Tecan Japan Co., Ltd., Kawasaki, Japan).

\subsection{Measurement of phospholipid concentration}

The identical CAD treatment process was applied to RAW264 cells grown in cell-culture dishes. Total lipids in the cells were extracted according to Folch et al. [18] with minor modifications [17]. The phosphorus concentration in the lipid extracts was determined by molybdenum blue method after degradation with sulfuric acid according to Fiske et al. [19] with minor modifications [20]. The absorbance at $830 \mathrm{~nm}$ was measured with a spectrophotometer. The total protein content of the cells was determined by using a Modified Lowry Protein Assay Kit (Thermo Fisher Scientific; Waltham, MA, USA) following the instruction manual. The absorbance at 620 nm was measured with a microplate reader.

\subsection{Measurement of the phospholipid and cellular CAD by HPLC-MS/MS}

A Quattro Premier triple quadrupole mass spectrometer hyphenated with a 2795 separation module (Waters; Milford, MA, USA) was used. The HPLC-MS/MS conditions were as follows: Column, Kinetex $2.6 \mathrm{C} 8(5 \mathrm{~cm}$ $\times 2.1 \mathrm{~mm}$ ID, $2.6 \mu \mathrm{m}$, Phenomenex; Torrance, CA, USA); column temperature, $40{ }^{\circ} \mathrm{C}$; mobile phase, gradient with ammonium formate $(10 \mathrm{mM})$ and methanol (initial, $70 \%$ methanol; $1.5 \mathrm{~min}, 90 \%$; $15 \mathrm{~min}, 90 \%$; $16.5 \mathrm{~min}, 70 \%$; 18 min, $70 \%$ ); electrospray voltage, $+3 \mathrm{kV}$; cone voltage, +40 $\mathrm{V}$; collision energy, $40 \mathrm{eV}$. The selected reaction monitoring (SRM) transitions for the phosphatidylinositols (PIs) were as follows: precursor ion $\mathrm{m} / \mathrm{z} 903.5$ (for PI 38:4), 905.6 (for PI 38:3), 879.6 (for PI 36:2) and 881.6 (for PI $36: 1$, neutral loss of 277 . The SRM transition for di-docosahexaenoyl BMP (BMP 22:6_22:6) was $m / z 883.5$ $>$ 385.3. PC 17:0_17:0 was used as an internal standard (SRM transition, $m / z 806>269)$. Peak ratios were confirmed to be linear with the nominal concentration ratio in sample solutions using commercially available reference standard phosphatidylcholine [17]. The cell suspension in saline were mixed with acetonitrile $(1: 1)$ and subjected to sonication and centrifugation $(3000 \mathrm{~g}, 15 \mathrm{~min})$. The CAD concentration of the supernatant was measured by using HPLC-MS/MS system: Column, Xterra RP18 $(5 \mathrm{~cm} \times 2.1$ $\mathrm{mm}$ ID, $3.5 \mu \mathrm{m}$, Waters); column temperature, $40{ }^{\circ} \mathrm{C}$; mobile phase, gradient with formic acid $(0.5 \%)$ and methanol (initial, 10\% methanol; $1.0 \mathrm{~min}, 10 \% ; 3.0 \mathrm{~min}$, $90 \%$; $10 \mathrm{~min}, 90 \%$; $11.5 \mathrm{~min}, 10 \%$; $15 \mathrm{~min}, 10 \%)$. SRM transitions were as follows: chlorpromazine, $m / z 319.2>$ 246; imipramine, $281.3>207.9$; propranolol, $260.3>183.1$. Reserpine was used as an internal standard (SRM transition, $m / z 609.3>397.3)$.

\section{Results and discussion}

\subsection{Effect of egg PC on the cellular toxicity of CADs}

Fig. 1 shows the viability curve of RAW264 cells treated with imipramine. Sigmoidal curves showing low viability at large imipramine concentration were obtained. The imipramine concentration giving $50 \%$ cellular viability is known as the $50 \%$ inhibitory concentration $\left(\mathrm{IC}_{50}\right)$, and this parameter is used to monitor toxicity. Table 1 lists the $\mathrm{IC}_{50}$ values of the cells treated with CADs. The $\mathrm{IC}_{50}$ values were significantly increased by co-treatment of CAD with egg PC ( $p<0.01$, Student's $t$-test). In contrast, egg PC alone showed decreased viability $(81.5 \%$ of control cells, $p$ 


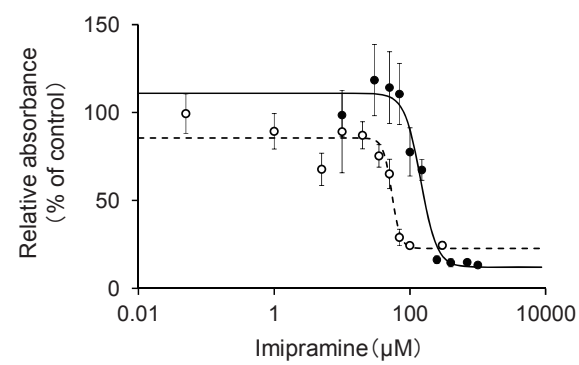

Fig. 1. Viability curves of RAW264 cell line treated with imipramine. $\circ$ : imipramine alone, $\bullet$ : with egg PC $(2 \mathrm{mM})$. Viability was indicated as relative absorbance ( $v s$. cells treated with vehicles). Mean $\pm S E(n=3)$.

$<0.01$, Student's $t$-test). There were two possible reasons for these observations: a large portion of the CADs remained outside of the cells, or the cytotoxicity of the CADs was reduced by egg PC. In order to confirm whether CAD was taken in the cell, the contents of the CADs were then measured. Table 2 lists the cellular CAD amounts corrected with protein. The CAD content showed an almost linear relationship with the nominal concentrations of CADs in the culture mediums, which suggested that co-treatment of CAD with egg PC did not disturb CAD uptake into cells. From the results in Tables 1 and 2, it was concluded that co-treatment of egg PC with CADs reduced the toxicity of CADs.

Table 1. IC $\mathrm{I}_{50}$ values of RAW264 cells treated with CAD.

\begin{tabular}{llll}
\hline & chlorpromazine & imipramine & propranolol \\
\hline CAD alone & $29.1 \pm 1.68$ & $50.1 \pm 2.70$ & $133 \pm 12.7$ \\
with egg PC a & $76.1 \pm 5.76^{*}$ & $143 \pm 3.0^{*}$ & $272 \pm 19.6^{*}$ \\
\hline
\end{tabular}

The $\mathrm{IC}_{50}$ values $(\mu \mathrm{M})$ were determined by curve-fitting of the 4-parameter equation to three sets of data. a: $2 \mathrm{mM} . \quad *: p<0.05$ (vs CAD alone, Student's $t$-test).

Table 2. CAD uptake in RAW 264 cells.

\begin{tabular}{|c|c|c|c|}
\hline CAD & CAD alone & with egg $\mathrm{PC}^{\mathrm{a}}$ & ratio \\
\hline \multicolumn{4}{|l|}{ chlorpromazine } \\
\hline treatment level $(\mu \mathrm{M})$ & 10 & 50 & 5.00 \\
\hline cellular uptake $\mathrm{b}^{\mathrm{b}}$ & $7.50 \pm 1.03$ & $39.4 \pm 1.51$ & 5.25 \\
\hline \multicolumn{4}{|l|}{ imipramine } \\
\hline treatment level $(\mu \mathrm{M})$ & 15 & 50 & 3.33 \\
\hline cellular uptake ${ }^{b}$ & $7.70 \pm 2.16$ & $33.8 \pm 5.51$ & 4.39 \\
\hline \multicolumn{4}{|l|}{ propranolol } \\
\hline treatment level $(\mu \mathrm{M})$ & 50 & 150 & 3.00 \\
\hline cellular uptake $\mathrm{b}^{\mathrm{b}}$ & $33.8 \pm 1.75$ & $74.4 \pm 5.61$ & 2.20 \\
\hline
\end{tabular}

Mean $\pm S D(n=3)$. a: $2 \mathrm{mM}$, b: $\mu \mathrm{mol} / \mathrm{g}$ protein.

\subsection{Effect of egg PC on the cellular phospholipid content and DIPL biomarkers}

Although the above results suggested a reduction of CAD toxicity with egg PC, it remains unclear whether the cellular phospholipid content increases by CAD when co-treated with egg PC. We assayed the phospholipid content in RAW264 cells after imipramine treatment with or without egg PC. The results are listed in Table 3. In the imipramine treatment, the phospholipid content increased more than 1.4 times, which was in accordance with a previous study [20]. When egg PC was co-treated with imipramine $(50 \mu \mathrm{M})$, however, the cellular phospholipid level increased equivalent to that of the imipramine treatment alone, although imipramine at this concentration was less toxic with egg PC than imipramine alone. This result suggests that accumulation of phospholipid is not an adverse effect in itself and that co-treatment of egg PC decreases CAD toxicity without affecting cellular phospholipid accumulation of CAD.

Table 3. Phospholipid content in RAW264 cells with/without imipramine or egg PC treatment.

\begin{tabular}{lcc}
\hline & without egg PC & with egg PC a \\
\hline without imipramine $^{\text {a }}$ & $4.76 \pm 0.67$ & $7.33 \pm 0.29^{*}$ \\
with imipramine $^{\mathrm{b}}$ & $6.72 \pm 0.11^{*}$ & $6.97 \pm 0.58^{*}$ \\
\hline
\end{tabular}

Mean $\pm S D$ (mg/g protein). $n=9$ for double negative control (ethanol), $n=3$ for IMI, egg PC and double treatment. a: $2 \mathrm{mM}$, b: $50 \mu \mathrm{M} . \quad *: p<0.01$ ( $v s$ double negative control, Mann-Whitney $U$ test).

We then studied the levels of DIPL biomarkers after CAD treatment with/without egg PC. Because the direct endpoint of DIPL is accumulation of phospholipid, we used phospholipid biomarkers BMP and PIs. Levels of BMP 22:6_22:6 and the ratios of (PI 38:3 + PI 38:4) over (PI 36:1 + PI 36:2) were measured by using HPLC-MS/MS. Typical chromatograms of phosphatidylinositols were shown in Fig. 2. The multiple peaks observed, suggesting structural isomers, were integrated together for each mass transition. The determined values of the biomarkers were listed in Table 4. Imipramine $(50 \mu \mathrm{M}$, approximately equivalent to $\mathrm{IC}_{50}$ ) treatment did not have a significant effect on BMP 22:6_22:6, whereas the PI ratio increased significantly. The reason why the biomarkers give inconsistent results is not clear. A possible reason is that the BMP 22:6_22:6 level is decreased by cellular damage, whereas the PI ratio is not affected by toxicity. The observations suggest that BMP 22:6_22:6 does not always reflect the cellular phospholipid content and that cellular toxicity may cause false-negative results in the BMP assay. In contrast, BMP 22:6_22:6 was significantly increased by imipramine $\left(50 \mu \mathrm{M}\right.$, obviously less than $\left.\mathrm{IC}_{50}\right)$ co-treated with egg PC. Our preliminary study using the same HPLC-MS/MS system revealed that BMP 22:6_22:6 was not detected in egg PC. Taking it into consideration that imipramine toxicity is reduced by egg $\mathrm{PC}$, the increase in BMP 22:6 22:6 suggests that BMP 22:6_22:6 does not 
reflect CAD toxicity. The BMP 22:6_22:6 level may change in relation to the cellular phospholipid content only in less damaged conditions. On the other hand, the PI ratio decreased after co-treatment of imipramine $(50 \mu \mathrm{M})$ with egg PC, which was in accordance with the toxicity data. Although the mechanism of this result is unknown, the PI ratio becomes large with increases in cellular phospholipid content concurrent with cellular toxicity. Our data in this study suggest that the PI ratio is a specific DIPL biomarker reflecting phospholipid accumulation concomitant with cellular toxicity.

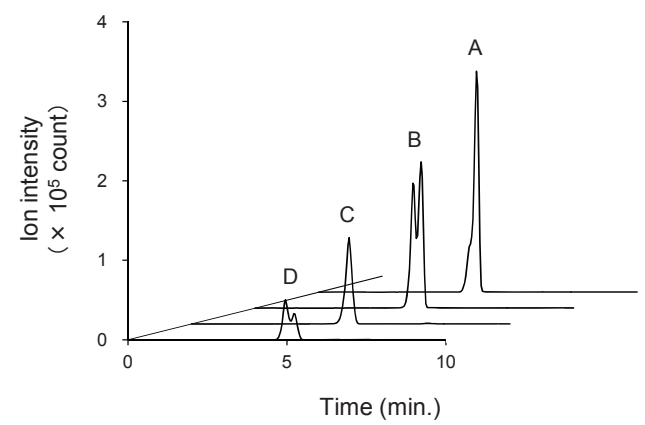

Fig. 2. Chromatograms of the marker PIs in RAW264 cells. A: PI 38:4, B: PI 38:3, C: PI 36:2, D: PI 36:1.

Table 4. Levels of biomarkers in RAW264 cells with/without imipramine or egg PC treatment.

\begin{tabular}{lll}
\hline & without egg PC & with egg PC $^{\text {a }}$ \\
\hline $\begin{array}{l}\text { PI ratio } \\
\text { without imipramine }\end{array}$ & $0.457 \pm 0.064$ & $0.210 \pm 0.003^{*}$ \\
$\begin{array}{l}\text { with imipramine } \\
\text { BMP }\end{array}$ & $1.22 \pm 0.509^{*}$ & $0.262 \pm 0.006^{*}$ \\
$\begin{array}{l}\text { without imipramine } \\
\text { with imipramine }^{\mathrm{b}}\end{array}$ & $0.417 \pm 0.371$ & $0.999 \pm 0.595$ \\
& $0.382 \pm 0.190$ & $0.546 \pm 0.099$ \\
\hline
\end{tabular}

Mean $\pm S D . \quad n=9$ for double negative control (ethanol), $n=3$ for IMI, egg PC and double treatment. a: $2 \mathrm{mM}$, b: $50 \mu \mathrm{M}$. $\quad *$ : $p<$ 0.01 ( $v s$ double negative control, Mann-Whitney $U$ test).

\section{Conclusions}

In the present study, we evaluated the $\mathrm{IC}_{50}$ values of RAW264 cells treated with CADs alone or co-treatment with egg PC to determine the biological meaning of DIPL. Furthermore, we compared the performance of the DIPL biomarkers BMP 22:6_22:6 and the PI ratio using the same cell culture. Our results showed that egg PC co-treated with propranolol, imipramine or chlorpromazine decreased the cellular toxicity of these CADs, which supports the hypothesis that DIPL works as a biological defense. In addition, the PI ratio increased when cellular phospholipid accumulation occurred concurrently with cellular toxicity. The PI ratio did not increase after co-treatment with CAD and egg PC, which was in accordance with the reduction of CAD toxicity with egg PC. Our results suggest that the PI ratio is a novel DIPL biomarker that enables specific detection of phospholipid accumulation concomitant with cellular toxicity by CADs.

\section{Acknowledgement}

The authors cordially thank Ms. Yuka Shirase for her skillful assistance.

\section{References}

[1] Kodavanti, U. P.; Mehendale, H. M. Pharmacol. Rev. 1990, 42, 327-354.

[2] Schmitz, G.; Grandl, M. Biochim. Biophys. Acta 2009, 1791, 524-539.

[3] Ueno, H.; Watanabe, M.; Hayashi, N.; Fukushima, A.; Yagyu, K. Ganka 2008, 50, 951-957.

[4] Zheng, N.; Zhang, X.; Rosania, G. R. J. Pharmacol. Exp. Ther. 2011, 336, 661-671.

[5] Martin, W. J., II; Standing, J. E. J. Pharmacol. Exp. Ther. 1988, 244, 774-779.

[6] Kuroda, Y.; Watanabe, Y.; Shibukawa, A.; Nakagawa, T. J. Pharm. Biomed. Anal. 2003, 30, 1869-1877.

[7] Kubo, M.; Gardner, M. F.; Hostetler, K. Y. Biochem. Pharmacol. 1986, 35, 3761-3765.

[8] Ma, J. Y.; Ma, J. K.; Weber, K. C. J. Lipid Res. 1985, 26, 735-744.

[9] Avdeef, A.; Box, K. J.; Comer, J. E.; Hibbert, C.; Tam, K. Y. Pharm. Res. 1998, 15, 209-215.

[10] Franzen, U.; Jorgensen, L.; Larsen, C.; Heegaard, N. H.; Østergaard, J. Electrophoresis 2009, 30, 2711-2719.

[11] Nicholls, A. W.; Nicholson, J. K.; Haselden, J. N.; Waterfield, C. J. Biomarkers 2000, 5, 410-423.

[12] Yudate, H. T.; Kai, T.; Aoki, M.; Minowa, Y.; Yamada, T.; Kimura, T.; Ono, A.; Yamada, H.; Ohno, Y.; Urushidani, T. Toxicology 2012, 295, 1-7.

[13] Hirode, M.; Ono, A.; Miyagishima, T.; Nagao, T.; Ohno, Y.; Urushidani, T. Toxicol. Appl. Pharmacol. 2008, 229, 290-299.

[14] Sawada, H.; Takami, K.; Asahi, S. Toxicol. Sci. 2005, 83, 282-292.

[15] Mortuza, G. B.; Neville, W. A.; Delaney, J.; Waterfield, C. J.; Camilleri, P. Biochim. Biophys. Acta 2003, 1631, 136-146.

[16] Baronas, E. T.; Lee, J. W.; Alden, C.; Hsieh, F. Y. Toxicol. Appl. Pharmacol. 2007, 218, $72-78$.

[17] Hamaguchi, R.; Tanimoto, T.; Kuroda, Y. $J$. Chromatogr. B 2014, 967, 110-117.

[18] Folch, J.; Lees, M.; Sloane Stanley, G. H. J. Biol. Chem. 1957, 226, 497-509.

[19] Fiske, C. H.; Subbarow, Y. Science 1929, 70, 381-382.

[20] Hamaguchi, R.; Haginaka, J.; Tanimoto, T.; Kuroda, Y. Cell Biol. Toxicol. 2014, 30, 67-77. 